Удк 615.32 .072

\title{
ОПРЕДЕЛЕНИЕ БИОЛОГИЧЕСКИ АКТИВНЫХ ВЕЩЕСТВ В ПЛОДАХ ОБЛЕПИХИ КРУШИНОВИДНОЙ (HIPPOPHAES RHAMNOIDES L.)
}

\author{
() О.В. Тринеева ", И.И. Сафонова, Е.Ф. Сафонова, А.И. Сливкин \\ Воронежский государственный университет, ул. Студенческая, 3, Воронеж, \\ 394006 (Россия), e-mail: lelik83@list.ru
}

По данным качественного, спектрального и хроматографического анализов, в свежих плодах облепихи содержатся флавоноиды (рутин и кверцетин) и каротиноиды ( $\beta$-каротин). Методами спектрофотометрии и титриметрии установлено количественное содержание дубильных веществ, органических кислот, флавоноидов, гидроксикоричных кислот и каротиноидов. Результаты составили соответственно $63,83 \pm 5,12 \% ; 20,61 \pm 0,68 \% ; 1,09 \pm 0,12 \% ; 0,40 \pm 0,02 \%$ и $52,29 \pm 2,11$ мг\% (в пересчете на абсолютно сухое сырье).

Ключевые слова: каротиноиды, флавоноиды, органические кислоты, дубильные вещества, гидроксикоричные кислоты, плоды облепихи свежие, стандартизация.

\section{Введение}

Облепиха крушиновидная (Hippophae rhamnoides, сем. Elaegnaceae) издавна известна как ценное лекарственное и пищевое растение, широко распространенное в Евразии [1]. Стандартизация свежих плодов облепихи проводится в соответствии с требованиями временной фармакопейной статьи (ВФС) 42-1741-87 [2]. Отечественные Государственные фармакопеи (ГФ) X и XI изд. не содержат статей на данный вид сырья. Свежие плоды облепихи крушиновидной включены в государственные реестры лекарственных средств 2004 и 2008 гг. В зарубежных ГФ ФС на данный вид лекарственного растительного сырья не обнаружено [3]. В соответствии с требованиями нормативной документации (НД) стандартизация и оценка качества плодов облепихи проводится по показателям, приведенным в таблице 1.

Биологически активные вещества (БАВ) в плодах облепихи, за исключением каротиноидов, согласно НД не определяют. По литературным данным [1], в плодах растения рода Hippophae содержится целый комплекс БАВ. Плоды облепихи широко используются в народной и официнальной медицине, поэтому исследования по разработке методик для стандартизации плодов облепихи по содержанию БАВ является весьма актуальными.

Цель настоящей работы - определение биологически активных веществ (флавоноидов, гидроксикоричных кислот, каротиноидов, органических кислот и дубильных веществ) в свежих плодах облепихи крушиновидной.

\footnotetext{
Тринеева Ольга Валерьевна - ассистент кафедры фармацевтической химии и фармацевтической технологии, кандидат фармацевтических наук, e-mail: lelik83@list.ru

Сафонова Ирина Игоревна - интерн кафедры фармации последипломного образования

Сафонова Елена Федоровна - заведующая кафедрой фармации последипломного образования, кандидат хим. наук, доцент, e-mail: safonova@pharmvsu.ru Сливкин Алексей Иванович - декан фармацевтического факультета, заведующий кафедрой фармацевтической химии и фармацевтической технологии, доктор фармацевтических наук, профессор, e-mail: slivkin@pharmvsu.ru
}

\section{Экспериментальная часть}

Объектом исследования служили свежие плоды растения рода Облепиха, собранные в Воронежской области в период полного созревания, согласно правилам заготовки данного вида лекарственного растительного сырья (ЛРС).

Качественный анализ с соком плодов подтвердил наличие флавоноидов, дубильных веществ, гидроксикоричных кислот, каротиноидов, органических кислот [4].

\footnotetext{
* Автор, с которым следует вести переписку.
} 
В литературе не были найдены данные по исследованию флавоноидов плодов облепихи методом ТСХ. Качественный анализ флавоноидных соединений проводили данным методом по ранее разработанной методике [5].

Для количественного определения флавоноидов в сырье облепихи разработана методика, основанная на их способности образовывать окрашенный комплекс со спиртовым раствором алюминия хлорида, с

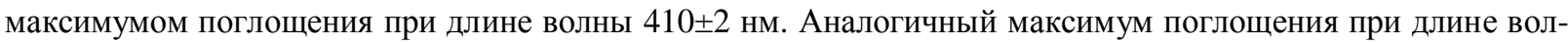
ны 413 2 нм отмечен для комплекса рутина со спиртовым раствором алюминия хлорида, использованного нами в методике в качестве стандартного образца (рис. 1).

Количественное определение гидроксикоричных кислот в плодах облепихи свежих проводили по разработанной методике прямой спектрофотометрии.

Суммарное содержание каротиноидов в пересчете на $\beta$-каротин определяли с помощью спектрофотометрии в видимой области [6].

Дубильные вещества определяли метод перманганатометрического титрования, включенного в ГФ X и XI изданий - метод Левенталя, изменённый А.Л. Курсановым, основан на способности дубильных веществ быстро окисляться перманганатом калия в присутствии индикатора - индигосульфокислоты.

Количественное определение суммы органических кислот в пересчете на яблочную кислоту проводили по методике ГФ ХІ [7].

Таблица 1. Стандартизация плодов облепихи

\begin{tabular}{l|c|c}
\hline \multicolumn{1}{c|}{ Показатель качества } & ВФС 42-1741-87 (свежие плоды) & ТУ 64-472-88 (сухие плоды) \\
\hline Макроскопия & + & - \\
Микроскопия & - & не более $10 \%$ \\
Влажность & - & не более $3 \%$ \\
Общая зола & - & не более $9 \%$ \\
Другие части облепихи & не более $1 \%$ & - \\
Плоды, поврежденные вредителями & не более $2 \%$ & - \\
Недозрелые плоды & не более $1 \%$ & - \\
Мятые плоды & не более $35 \%$ & не более $1 \%$ \\
Органические примеси & не более $1 \%$ & не более $0,5 \%$ \\
Минеральные примеси & не более $0,5 \%$ & не менее 40 мг\% \\
Содержание суммы каротиноидов & не менее 10 мг\% & не менее $15 \%$ \\
в пересчете на $\beta$-каротин & $8-12 \%$ & Содержание жирного масла
\end{tabular}

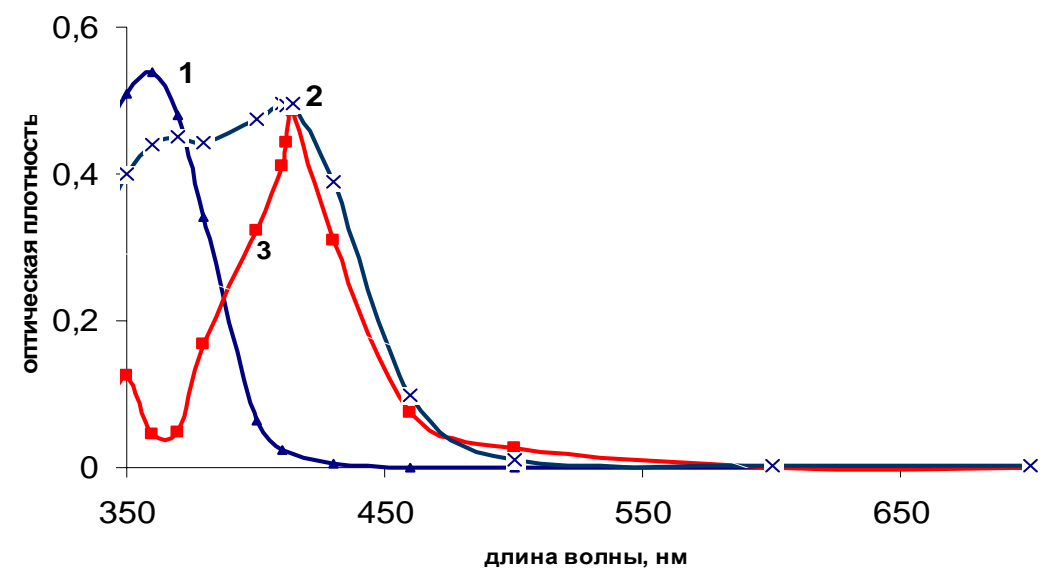

Рис. 1. Спектры поглощения (1 - спектр поглощения 0,0004\% спиртового раствора стандартного образца рутина; дифференциальные спектры поглощения комплексов рутина (2) и извлечения из плодов облепихи (3) с хлоридом алюминия)

\section{Обсуждение результатов}

На хроматограммах извлечения из свежих плодов облепихи [5] при нанесении 70 и 100 мкл пробы наблюдали 7 зон ( $\mathrm{R}_{\mathrm{f}}$ составило 0,$\left.08 ; 0,19 ; 0,32 ; 0,53 ; 0,64 ; 0,80 ; 0,99\right)$. При сравнении величин $\mathrm{R}_{\mathrm{f}}$ полученных хроматографических зон со стандартными образцами были идентифицированы рутин $\left(\mathrm{R}_{\mathrm{f}}=0,53 \pm 0,02\right)$, кверцетин $\left(\mathrm{R}_{\mathrm{f}}=0,8 \pm 0,02\right)$ и $\beta$-каротин $\left(\mathrm{R}_{\mathrm{f}}=0,99 \pm 0,01\right)$. Результаты идентификации хроматографических зон на хроматограмме извлечения из плодов облепихи представлены в таблице 2. 
Неидентифицированные зоны предположительно относятся к флавоноидам, так как имеют характерное свечение в УФ-свете, свойственное для флавоноидов [8-10]. Для каждой хроматографической зоны на хроматограмме были рассчитаны величины селективности сорбции (L) и коэффициент распределения (К) (табл. 2). Результаты свидетельствуют об удовлетворительном разделении хроматографи-
Таблица 2. Параметры хроматографического разделения зон на хроматограмме из свежих плодов облепихи

\begin{tabular}{l|c|c|c}
\hline \multicolumn{1}{c|}{ № зоны } & $\mathrm{R}_{\mathrm{f}}$ & $\mathrm{K}$ & $\mathrm{L}=\mathrm{K}_{1} / \mathrm{K}_{2}$ \\
\hline 1 - неидентифицированная зона & $0,08 \pm 0,01$ & 11,50 & \\
2 - неидентифицированная зона & $0,19 \pm 0,02$ & 4,30 & 2,67 \\
3 - неидентифицированная зона & $0,32 \pm 0,02$ & 2,13 & 2,02 \\
4 - рутин & $0,53 \pm 0,02$ & 0,89 & 2,40 \\
5 - неидентифицированная зона & $0,64 \pm 0,02$ & 0,56 & 1,58 \\
6 - кверцетин & $0,80 \pm 0,02$ & 0,25 & 2,25 \\
7 - $\beta$-каротин & $0,99 \pm 0,01$ & 0,01 & 25,00 \\
\hline
\end{tabular}
ческих зон флавоноидов на хроматограмме и правомерности использования данной методики [11].

Согласно разработанной методике [5] проводили полуколичественное определение рутина в общей сумме флавоноидов в извлечении из плодов облепихи. Полученное на хроматограмме извлечения пятно рутина по величине и интенсивности окраски соответствовало аналогичной хроматографической зоне на калибровочной хроматограмме стандартных растворов рутина [12]. Результаты свидетельствуют, что содержание рутина в извлечении составляет около $0,05 \%$.

Как видно из рисунка 1 , стандартный раствор рутина после взаимодействия с хлоридом алюминия имеет максимумы при 364 и 410 нм; а извлечение из плодов облепихи - при 414 нм. Согласно литературным данным, для получения наиболее стабильных результатов использовали в качестве комплексообразующего реагента $2 \%$ спиртовый раствор хлорида алюминия в соотношении экстракт - комплексообразователь 1 : 1 [13-18]. Известно также, что анализ необходимо проводить через 30 мин после добавления 2\% спиртового раствора хлорида алюминия к аликвоте извлечения из плодов облепихи [13-18]. Для извлечения суммы флавоноидов, согласно рекомендациям литературы, нами были использованы водноспиртовые смеси в различных соотношениях [8-10, 13-18]. В таблице 3 представлены данные по влиянию состава экстрагента на степень извлечения флавоноидов (в пересчете на рутин) из плодов облепихи. Лучшим экстрагентом для выделения флавоноидов из плодов облепихи является 70\% этанол. Из литературных источников известно, что оптимальным для извлечения флавоноидов из ЛРС является соотношение сырья и экстрагента $1: 30$, а наилучшее время экстракции, за которое будет извлекаться максимальное количество флавоноидов, составляет 45 мин [13-18]. По разработанной нами методике была проведена количественная оценка содержания данной группы БАВ в плодах облепихи свежих. Результаты статистической обработки определения суммы флавоноидов в пересчёте на рутин и абсолютно сухое сырье в плодах облепихи представлены в таблице 4.

Спектр поглощения извлечения из плодов облепихи в диапазоне длин волн 400-500 нм имеет мак-

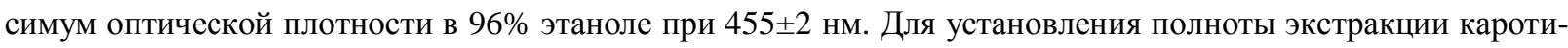
ноидов из плодов облепихи было изучено влияние полярности экстрагента. Для экстракции каротиноидов используют полярные растворители с достаточно высокими значениями полярности (Р'). Поэтому для извлечения суммы каротиноидов из плодов облепихи нами были использованы водно-спиртовые смеси в различных соотношениях и хлороформ, согласно рекомендациям литературы [20]. В таблице 3 представлены данные по влиянию состава экстрагента на степень извлечения каротиноидов из плодов облепихи. Лучшим экстрагентом для выделения каротиноидов из плодов облепихи является $96 \%$ этанол.

При исследовании влияния полярности экстрагента в диапазоне от 4,4 до 9,0 ед. на выход каротиноидов (рис. 2) установлено, что с увеличением полярности до 5,5 единиц происходит повышение экстрагируемости каротиноидов. Дальнейшее увеличение полярности экстрагента нецелесообразно ввиду снижения содержания каротиноидов в извлечении (рис. 2).

Результаты статистической обработки [7] определения суммы каротиноидов в пересчете на $\beta$-каротин и абсолютно сухое сырье в плодах облепихи свежих представлены в таблице 4.

Таблица 3. Влияние экстрагента на извлечение флавоноидов и каротиноидов из плодов облепихи

\begin{tabular}{l|c|c}
\hline Экстрагент & $\begin{array}{c}\text { Содержание ка- } \\
\text { ротиноидов, мг\% }\end{array}$ & $\begin{array}{c}\text { Содержание фла- } \\
\text { воноидов, \% }\end{array}$ \\
\hline 70\% этанол & 17,30 & $\mathbf{1 , 0 8 5}$ \\
$\mathbf{9 6 \%}$ этанол & $\mathbf{5 5 , 9 7}$ & 0,620 \\
хлороформ & 29,30 & - \\
Вода & 15,08 & 0,677 \\
\hline
\end{tabular}




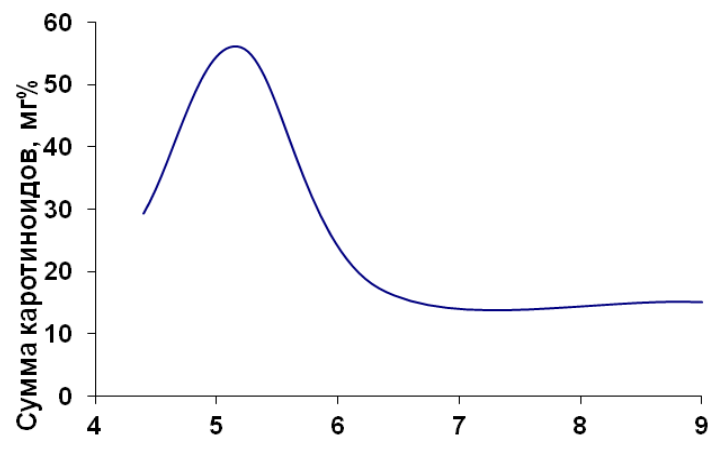

Полярность экстрагента (Р), ед. пол.

Рис. 2. Влияние полярности экстрагента на выход каротиноидов
Важными БАВ ЛРС являются гидроксикоричные кислоты. Они принимают участие в лечебном действии суммарных препаратов благодаря специфической биологической активности. Гидроксикоричные кислоты проявляют желчегонную, антимикробную, антимикозную, гепатопротекторную, противовоспалительную, иммунотропную активность, тормозят агрегацию эритроцитов, имеют бактериостатические свойства [19]. Вид спектра поглощения извлечения из свежих плодов облепихи, полученного как описано выше, в диапазоне длин волн 300-400 нм свидетельствует о присутствии максимума при длине волны $328 \pm 2$ нм, что характерно для гидроксикоричных кислот [19]. Результаты статистической обработки содержания

суммы гидроксикоричных кислот в пересчёте на кислоту хлорогеновую и абсолютно сухое сырье представлены в таблице 4 .

Дубильные вещества растительного происхождения представляют группу сложных органических соединений, являющихся производными многоатомных фенолов с разнообразной химической структурой, начиная от простейших производных полифенолов и заканчивая более сложными высокомолекулярными их производными, так называемыми флобафенами и флобатанинами. Согласно методу ГФ XI, при анализе проводится однократная экстракция сырья аналогично способу приготовления отвара, что позволяет определить количество дубильных веществ, получаемых при изготовлении отвара из данного сырья в домашних условиях [7]. Результаты определения суммы дубильных веществ в плодах облепихи в пересчете на абсолютно сухое сырье и метрологическая характеристика результата анализа представлены в таблице 4.

Одним из классов соединений, проявляющих широкий диапазон биологической активности, являются органические кислоты. Они обладают антиоксидантной, противовоспалительной, иммуномодулирующей активностью, принимают участие в обмене веществ, положительно влияют на усвоение пищи, создают благоприятные условия для жизнедеятельности полезных микроорганизмов кишечника. Комплекс органических кислот входит в состав косметических пилингов в качестве кератолитического компонента. Результаты определения суммы органических кислот в плодах облепихи в пересчете на абсолютно сухое сырье и метрологическая характеристика методики представлены в таблице 4.

Таблица 4. Метрологическая характеристика метода анализа $(\mathrm{P}=95 \%)$

\begin{tabular}{|c|c|c|c|c|c|c|c|c|c|}
\hline $\mathrm{n}$ & $\mathrm{f}$ & $\mathrm{X}_{\mathrm{cp}}$ & $\mathrm{S}^{2}$ & $\mathrm{~S}$ & $\mathrm{Sx}_{\mathrm{cp}}$ & $\mathrm{t}(\mathrm{P}, \mathrm{t})$ & $\Delta \mathrm{x}$ & $\Delta \mathrm{x}_{\mathrm{cp}}$ & $\varepsilon_{\mathrm{cp}}, \%$ \\
\hline \multicolumn{10}{|c|}{ Сумма флавоноидов, \% } \\
\hline 4 & 3 & 1,085 & 0,00577 & 0,0759 & 0,03795 & 3,18 & 0,24 & 0,1207 & 11,12 \\
\hline \multicolumn{10}{|c|}{ Сумма органических кислот, \% } \\
\hline 3 & 2 & 20,61 & 0,0757 & 0,275 & 0,159 & 4,30 & 1,1825 & 0,6835 & 3,32 \\
\hline \multicolumn{10}{|c|}{ Сумма каротиноидов, мг\% } \\
\hline 5 & 4 & 52,29 & 3,35 & 1,83 & 0,82 & 2,78 & 4,7 & 2,11 & 4,04 \\
\hline \multicolumn{10}{|c|}{ Сумма дубильных веществ, \% } \\
\hline 5 & 4 & 63,83 & 19,84 & 4,45 & 1,99 & 2,78 & 11,44 & 5,12 & 8,02 \\
\hline \multicolumn{10}{|c|}{ Сумма гидроксикоричных кислот, \% } \\
\hline 6 & 5 & 0,40 & 0,0004 & 0,02 & 0,0082 & 2,57 & 0,0514 & 0,021 & 5,24 \\
\hline
\end{tabular}

\section{Выводы}

1. По данным хроматографического анализа, в плодах облепихи содержатся 6 веществ флавоноидной природы, два из которых идентифицированы как рутин и кверцетин, и каротиноид ( $\beta$-каротин).

2. Методом прямой спектрофотометрии установлено количественное содержание гидроксикоричных кислот и каротиноидов в свежих плодах облепихи крушиновидной.

3. Титриметрически проведено количественное определение дубильных веществ и суммы органических кислот в плодах. 
4. Методом дифференциальной спектрофотометрии установлено количественное содержание флавоноидов.

5. Разработанные методики могут быть рекомендованы для включения в современную НД на свежие плоды облепихи крушиновидной.

6. Результаты свидетельствует о перспективности использования плодов облепихи в практической медицине не только в качестве источника жирного масла, но и в качестве ЛРС - дополнительного источника БАВ различных классов.

\section{Список литературы}

1. Лекарственные растения, сырье и фитопрепараты / под ред. С.Е. Дмитрука. Томск, 2004. Ч. I. 116 с.

2. Богачева Н.Г., Кокушкина Н.П., Сокольская Т.А. Стандартизация лекарственного растительного сырья облепихи крушиновидной // Фармация. 2001. №1. С. 27-29.

3. Киселева Т.Л., Смирнова Ю.А. Лекарственные растения в мировой медицинской практике: государственное регулирование номенклатуры и качества. М., 2009. 295 с.

4. Георгиевский В.П., Комисаренко Н.Ф., Дмитрук С.Е. Биологически активные вещества лекарственных растений. Новосибирск, 1990. 333 с.

5. Чечета О.В., Сливкин А.И., Сафонова И.И. Выбор оптимальных параметров хроматографического определения рутина методом ТСХ // Фармобразование-2010: материалы 4-й Всерос. с междунар. участием науч.метод. конф. Воронеж, 2010. Ч. II. С. 407-410.

6. Купянская В.Н. Получение и исследование соединения облепихового масла с $\beta$-циклодекстрином // Вестник ВГУ. Серия: Химия, Биология, Фармация. 2004. №2. С. 222-224.

7. Государственная фармакопея. ХІ изд. Вып. 2. М., 1990. С. 226-377.

8. Луценко С.В., Фельдман Н.Б., Быков В.А. Растительные флаволигнаны. Биологическая активность и терапевтический потенциал. М., 2006. 236 с.

9. Корулькин Д.Ю., Ж.А. Абилов, Р.А. Музычкина, Г.А. Толстиков. Природные флавоноиды. Новосибирск, 2007. $232 \mathrm{c}$.

10. Клышев Л.К., Бандюкова В.А., Алюкина Л.С. Флавоноиды растений. Алма-Ата, 1978. 220 с.

11. Гейсс Ф. Основы тонкослойной хроматографии. М., 1999. 405 с.

12. Березкин В.Г., Бочков Н.С. Количественная тонкослойная хроматография. М., 1980. 183 с.

13. Бубенчикова В.Н., Дроздова И.Л. Разработка показателей качества листьев земляники лесной // Фармация. 2002. №6. С. 16-18.

14. Самылина И.А., Терешина Н.С. Сравнительное изучение настоек календулы // Фармация. 2005. №6. С. 6-8.

15. Высочина Г.И., Шалдаева Т.М., Коцупий О.В., Храмова Е.П. Флавоноиды Мари белой (Chenopodium album L.), произрастающей в сибири // Химия растительного сырья. 2009. №4. С. 107-112.

16. Федосеева Л.М., Тимохин Е.В. Изучение флавоноидов красных листьев бадана толстолистного, произрастающего на Алтае // Химия растительного сырья. 1999. №4. С. 81-84.

17. Шарова О.В., Куркин В.А. Флавоноиды цветков календулы лекарственной // Химия растительного сырья. 2007. №1. С. 65-68.

18. Куркин В.А., Артамонова Е.С. Определение флавоноидов в траве чистотела большого // Фармация. 2007. №5. C. $10-12$.

19. Бурда Н.Е., Журавель И.А., Кисличенко В.С., Демехин В.Б. Количественное определение гидроксикоричных кислот в траве и подземных органах Filipenduli ulmaria (L.) maxim // Традиции и инновации фармацевтической науки и практики : материалы Всероссийской научно-практическая конф. с международным участием. Курск, 2011. С. 209-212.

20. Шелестова В.В. Современные подходы к стандартизации лекарственных средств, содержащих каротиноиды: бета-каротин и ликопин: автореф. дис. ... канд. фарм. наук. М., 2002. 25 с.

Поступило в редакичию 6 ноября 2012 г. 
Trineeva O.V., Safonova I.I., Safonova E.F., Slivkin A.I. DEFINITION OF BIOLOGICALLY ACTIVE SUBSTANCES IN FRUITS OF HIPPOPHAES RHAMNOIDES L.

Voronezh State University, ul. Studencheskaia, 3, Voronezh, 394006 (Russia),e-mail: lelik83@list.ru

According to spectral and chromatography analyses, in fruits of Hippophaes rhamnoides contain of flavonoides (routine and quercetine) and carotinoides ( $\beta$-carotine). Methods of a spectrophotometry and a titrimetry established the quantitative content of tannins, organic acids, flavonoides, oxycoriches acids and carotinoides. Results made respectively $63,83 \pm 5,12 \%$; $20,61 \pm 0,68 \% ; 1,09 \pm 0,12 \% ; 0,40 \pm 0,02 \%$ and $52,29 \pm 2,11 \mathrm{mg} \%$.

Keywords: carotinoides, flavonoides, organic acids, tannins, oxycoriches acids, fruits of Hippophaes rhamnoides fresh, standartisation.

\section{References}

1. Lekarstvennye rasteniia, syr'e i fitopreparaty. Ed. Dmitruk S.E. [Medicinal plants and herbal raw materials. Ed. Dmitruk S.E.]. Tomsk, 2004, part. 1, 116 p. (in Russ.).

2. Bogacheva N.G., Kokushkina N.P., Sokol'skaia T.A. Farmatsiia, 2001, no. 1, pp. 27-29. (in Russ.).

3. Kiseleva T.L., Smirnova Iu.A. Lekarstvennye rasteniia v mirovoi meditsinskoi praktike: gosudarstvennoe regulirovanie nomenklatury $i$ kachestva. [Medicinal plants in the world medical practice: state regulation range and quality]. Moscow, 2009, 295 p. (in Russ.).

4. Georgievskii V.P., Komisarenko N.F., Dmitruk S.E. Biologicheski aktivnye veshchestva lekarstvennykh rastenii. [Biologically active substances of medicinal plants]. Novosibirsk, 1990, 333 p. (in Russ.).

5. Checheta O.V., Slivkin A.I., Safonova I.I. Farmobrazovanie-2010: materialy 4-i vserossiiskoi s mezhdunarodnym uchastiem nauchno-metodicheskoi konferentsii. [Farmobrazovanie 2010: Proceedings of the 4th All-Russian with international participation Scientific Conference]. Voronezh, 2010, part. II, pp. 407-410. (in Russ.).

6. Kupianskaia V.N. Vestnik VGU. Seriia: Khimiia, Biologiia, Farmatsiia, 2004, no. 2, pp. 222-224. (in Russ.).

7. Gosudarstvennaia farmakopeia XI izd. [State Pharmacopoeia XI ed.]. Moscow, 1990, part. 2, pp. 226-377. (in Russ.).

8. Lutsenko S.V., Fel'dman N.B., Bykov V.A. Rastitel'nye flavolignany. Biologicheskaia aktivnost' $i$ terapevticheskii potentsial. [Vegetable flavolignany. Biological activity and therapeutic potential.]. Moscow, 2006, 236 p. (in Russ.).

9. Korul'kin D.Iu., Zh.A. Abilov, R.A. Muzychkina, G.A. Tolstikov. Prirodnye flavonoidy. [Natural flavonoids.]. Novosibirsk, 2007, 232 p. (in Russ.).

10. Klyshev L.K., Bandiukova V.A., Aliukina L.S. Flavonoidy rastenii. [Flavonoids are plant.]. Alma-Ata, 1978,220 p. (in Russ.).

11. Geiss F. Osnovy tonkosloinoi khromatografii. [Basics TLC.]. Moscow, 1999, 405 p. (in Russ.).

12. Berezkin V.G., Bochkov N.S. Kolichestvennaia tonkosloinaia khromatografiia. [Quantitative thin-layer chromatography]. Moscow, 1980, 183 p. (in Russ.).

13. Bubenchikova V.N., Drozdova I.L. Farmatsiia, 2002, no. 6, pp. 16-18. (in Russ.).

14. Samylina I.A., Tereshina N.S. Farmatsiia, 2005, no. 6, pp. 6-8. (in Russ.).

15. Vysochina G.I., Shaldaeva T.M., Kotsupii O.V., Khramova E.P. Khimiia rastitel'nogo syr'ia, 2009, no. 4, pp. $107-112$. (in Russ.).

16. Fedoseeva L.M., Timokhin E.V. Khimiia rastitel'nogo syr'ia, 1999, no. 4, pp. 81-84. (in Russ.).

17. Sharova O.V., Kurkin V.A. Khimiia rastitel'nogo syr'ia, 2007, no. 1, pp. 65-68. (in Russ.).

18. Kurkin V.A., Artamonova E.S. Farmatsiia, 2007, no. 5, pp. 10-12. (in Russ.).

19. Burda N.E., Zhuravel' I.A., Kislichenko V.S., Demekhin V.B. Traditsii $i$ innovatsii farmatsevticheskoi nauki $i$ praktiki: Vserossiiskaia nauchno-prakticheskaia konferentsiia s mezhdunarodnym uchastiem. [Tradition and innovation of pharmaceutical science and practice: Russian scientific-practical conference with international participation.]. Kursk, 2011, pp. 209-212. (in Russ.).

20. Shelestova V.V. Sovremennye podkhody $k$ standartizatsii lekarstvennykh sredstv, soderzhashchikh karotinoidy: betakarotin i likopin: avtoref. ... kand. farm. nauk. [Modern approaches to standardization of drugs containing carotenoids: beta-carotene and lycopene: abstract Candidate of Pharmaceutical Sciences]. Moscow, 2002, 25 p. (in Russ.).

Received November 6, 2012

Revised September 16, 2013

\footnotetext{
* Corresponding author.
} 